\title{
Problems of Infocommunications.
} Science and Technology

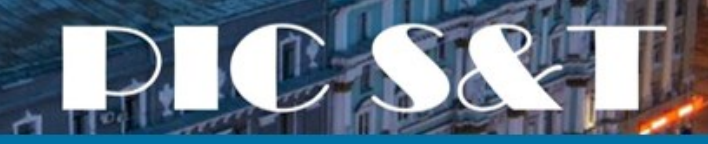

\section{Blockchain as a Transaction Protocol for Guaranteed Transfer of Values in Cluster Economic Systems with Digital Twins}

Sergiy Obushnyi, Roman Kravchenko, Yevhenif Babichenko Borys Grinchenko Kyiv University (Kyiv, Ukraine), 482.solutions (Odesa, Ukraine)

IEEE $\%$ UKRAINE SECTION
DIC SAT" 2019
- IEEE Advancing Technology
for Humanity 


\section{Introduction}

1Expertise 482.solutions

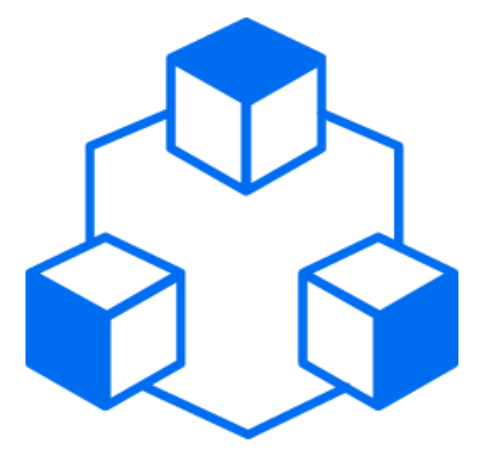

P2P / Distributed [Ledger] Technology

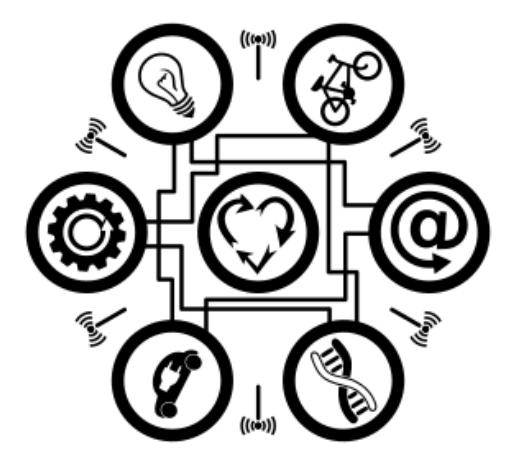

M2M / Internet of Things 


\section{Introduction}

> $R \& D$, Science \& Education

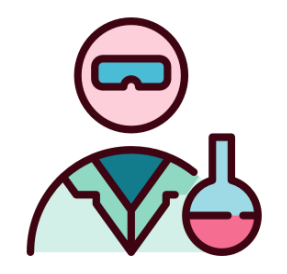

- Digital twins protocols

- Distributed infrastructure

- P2P economic models

- Applied issues of DLT
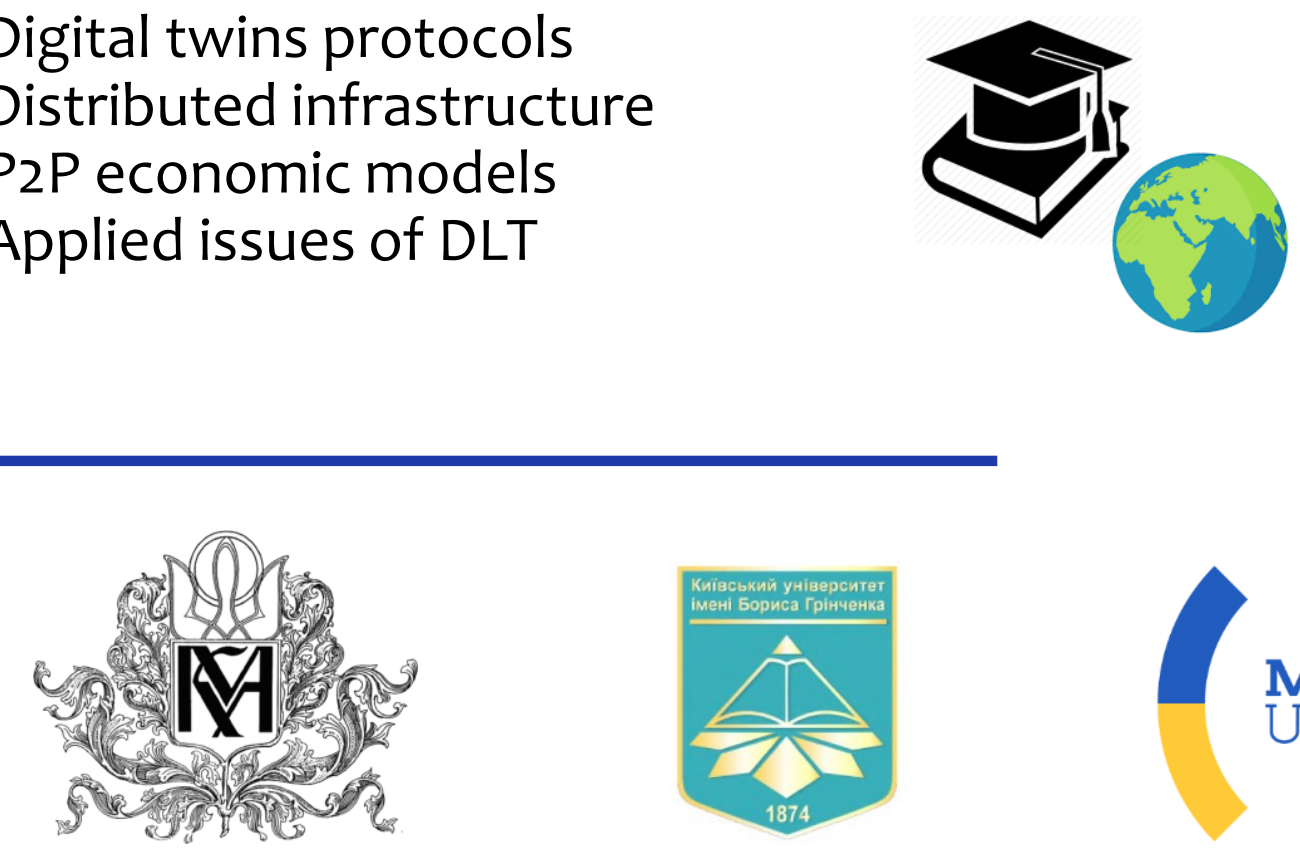


\section{Problem Formulation}

> How we can guarantee trust for digital twin?

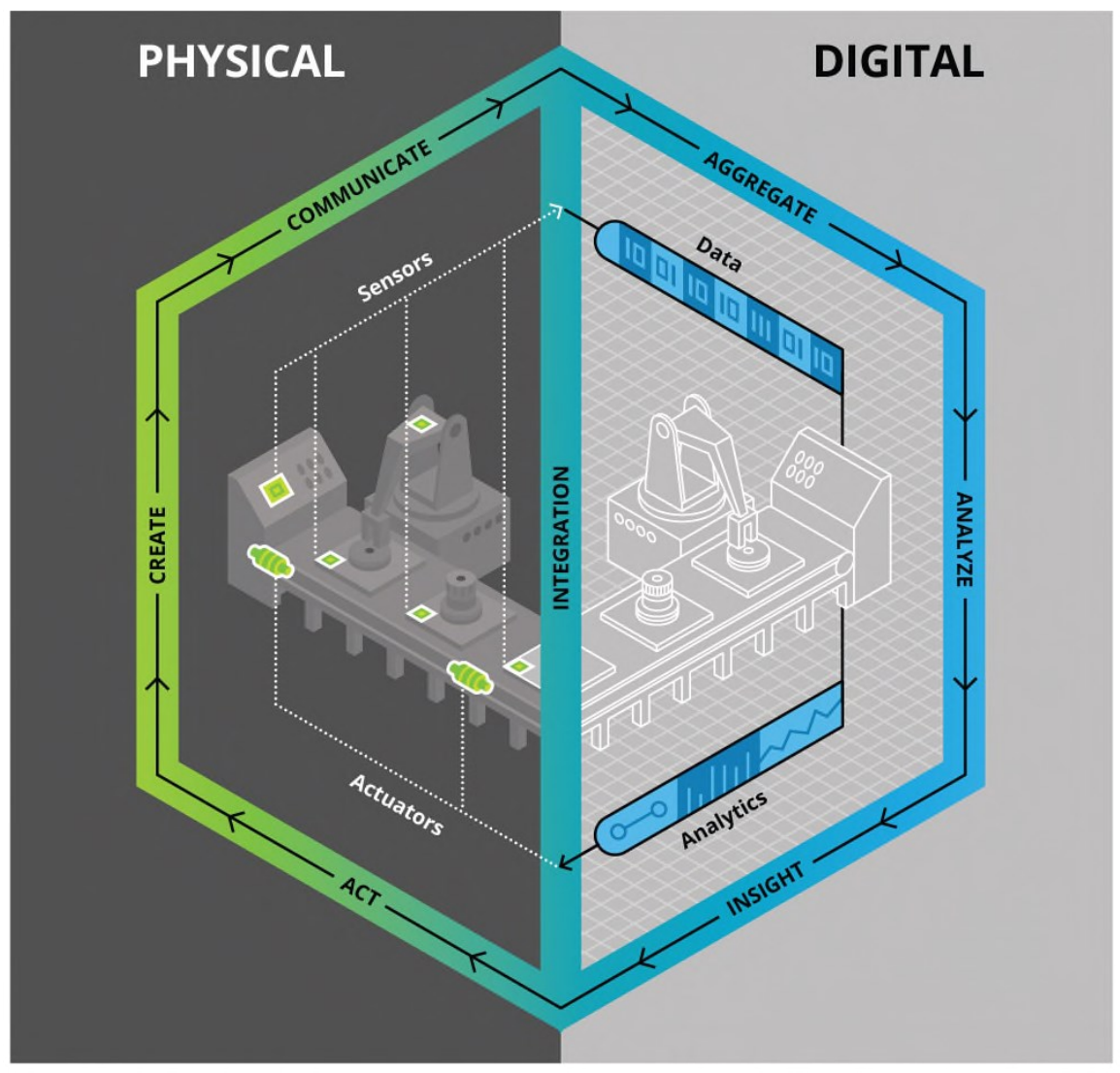




\section{Problem Formulation}

> Transaction Cost Theory (Ronald H. Coase)

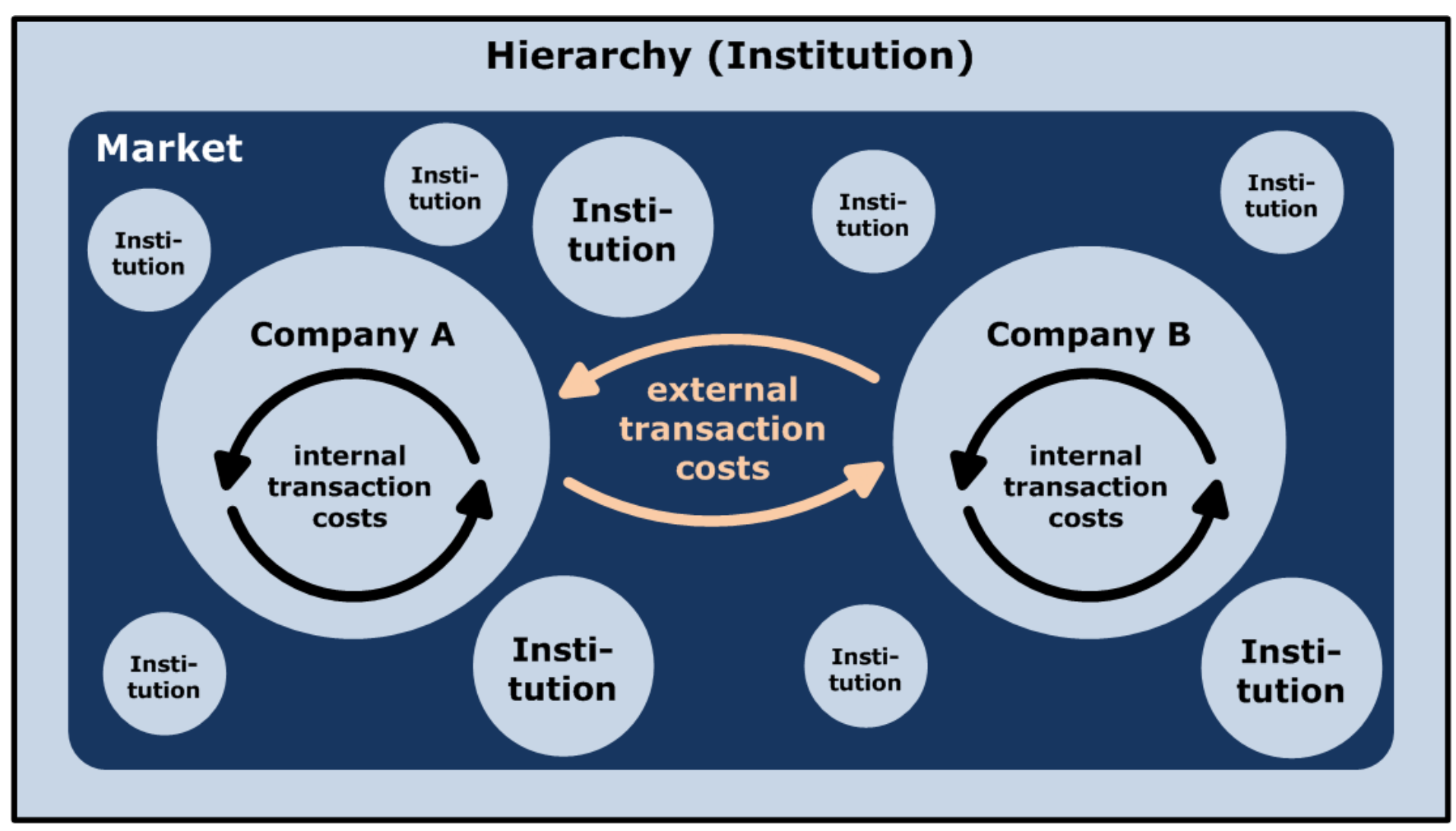




\section{Problem Formulation}

1 P2P cluster's economy and value's ownership transfer
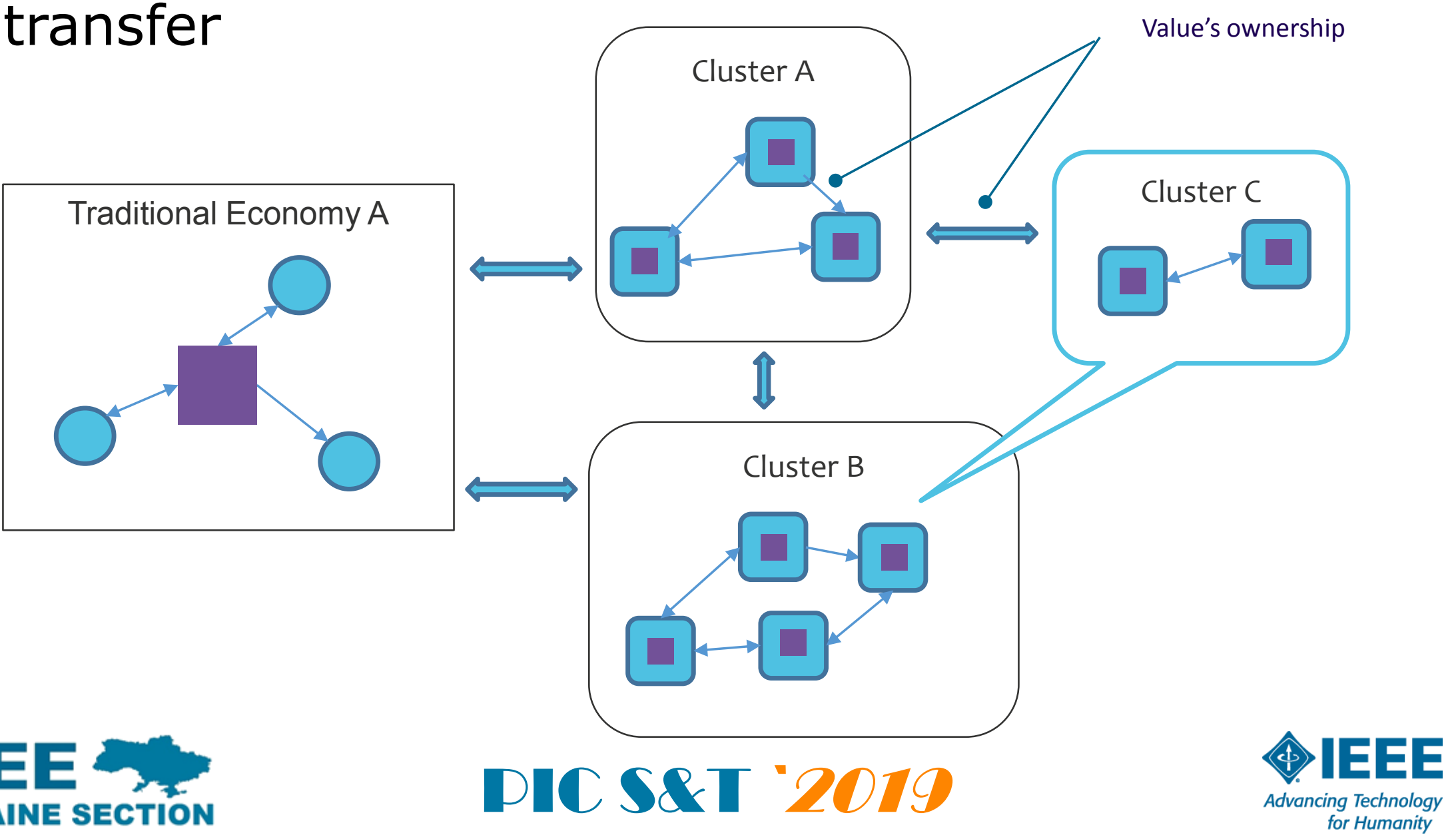


\section{Methods}

> Mealy machine and Economic Effect

$$
\begin{aligned}
& \delta: S \times X \rightarrow S \\
& \lambda: S \times X \rightarrow Y \\
& M=\left(S, S_{0}, X, Y, \delta, \lambda\right) .
\end{aligned}
$$

where $\mathrm{S}$ - the set of all possible internal states of the system;

$\mathrm{S}_{0}$ is the initial state of the system;

$\mathrm{X}$ is external impacts on the system;

$\mathrm{Y}$ is system outputs (its impact on the environment);

$\delta$ is transition function, determining the change in the internal system's state;

$\lambda$ - output function, which determines the impact on the environment.

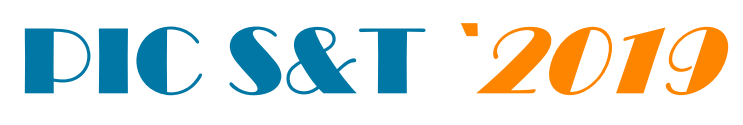




\section{Methods}

> Blockchain as notary for the digital twins

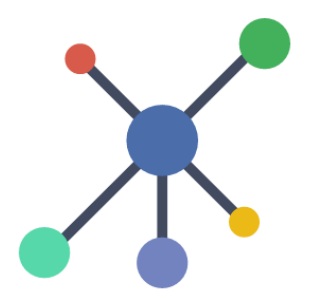

p2p network

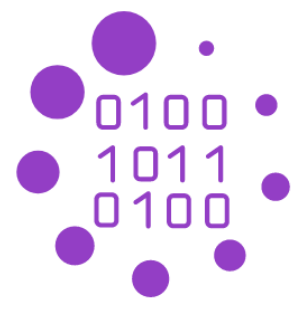

p2p transactions protocol

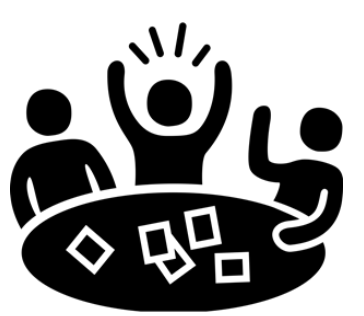

Consensusbased

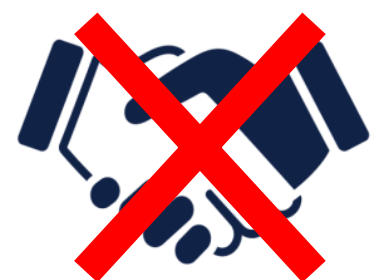

Point of trust 


\section{Methods}

> Trusted Execution Environment (TEE)

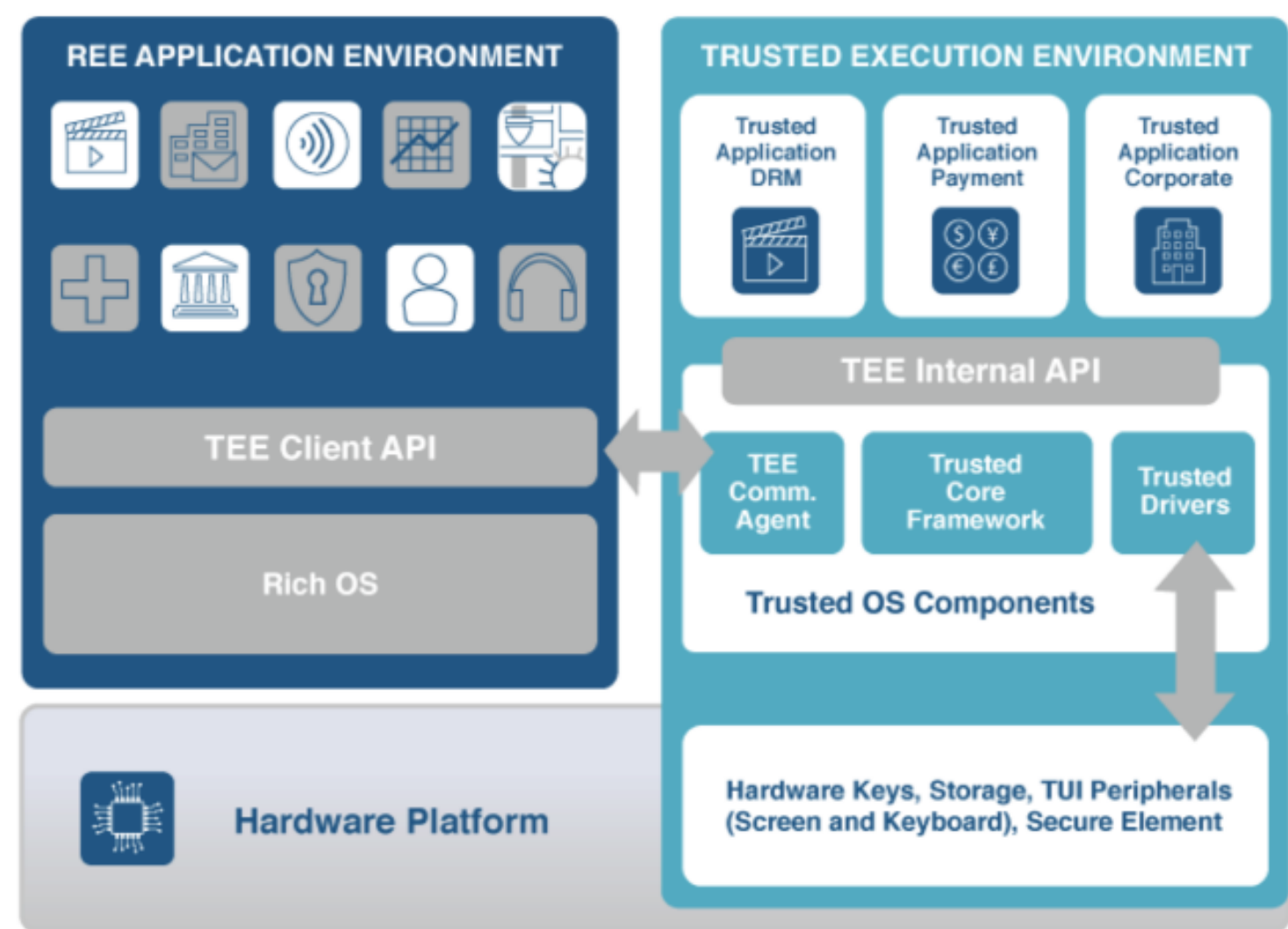




\section{Results: Model of digital twin interaction based on blockchain}

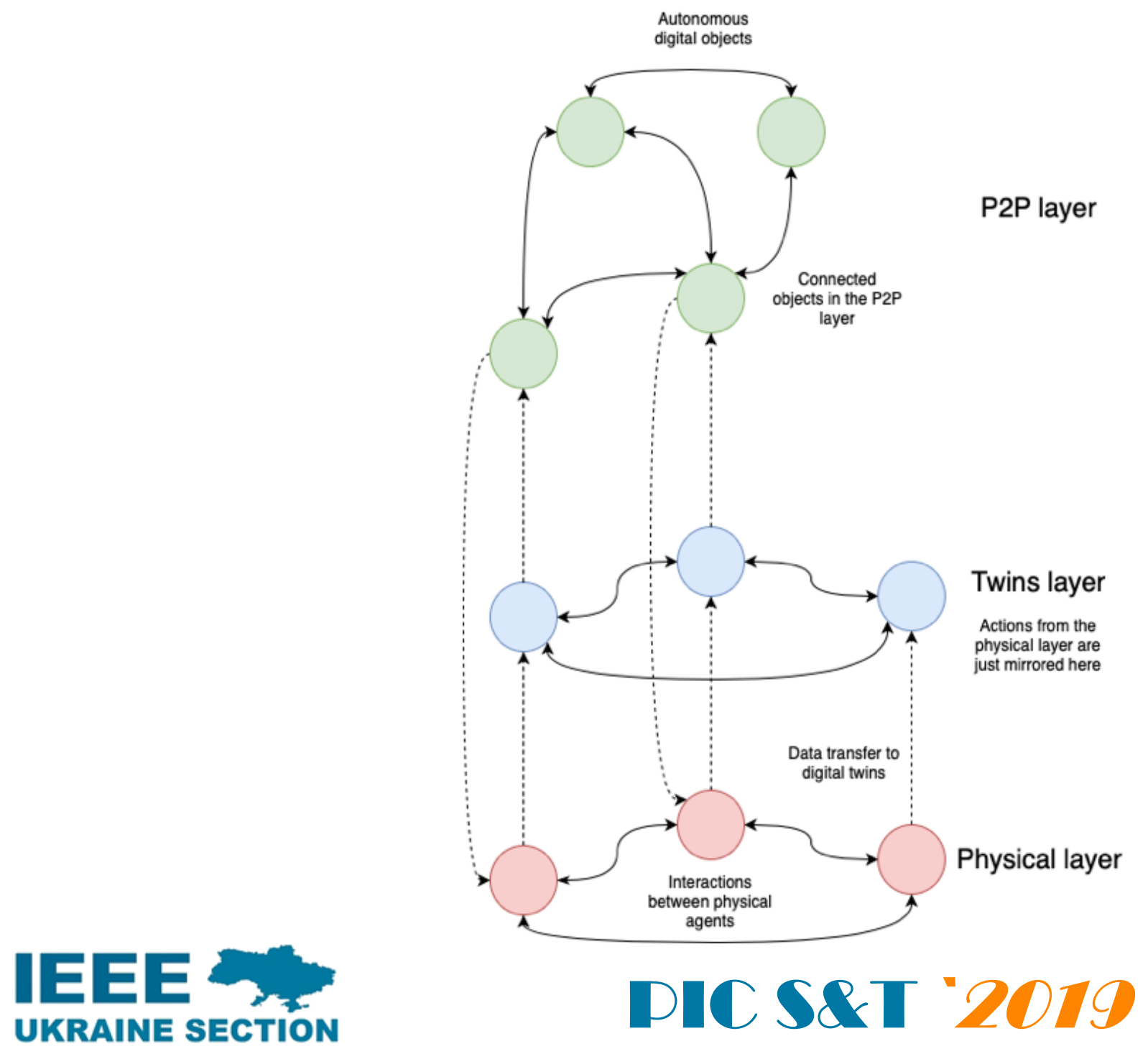




\section{Conclusions}

> Digital twins of energy smart grids and blockchain
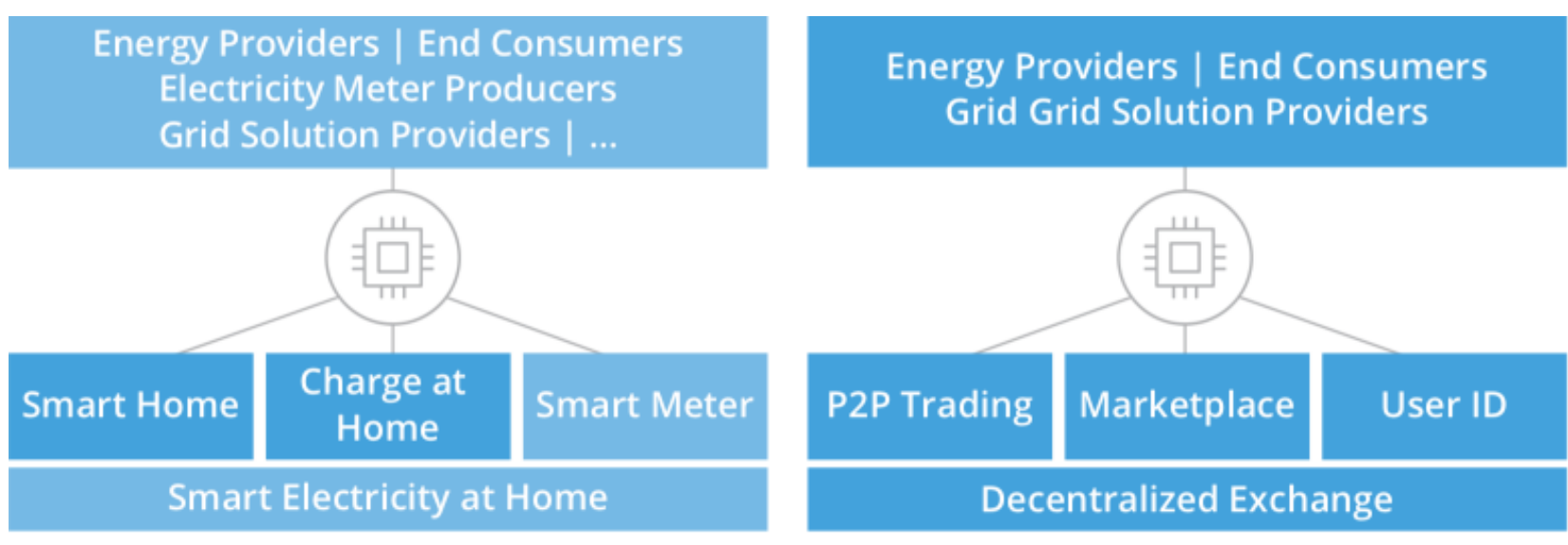

\section{全}
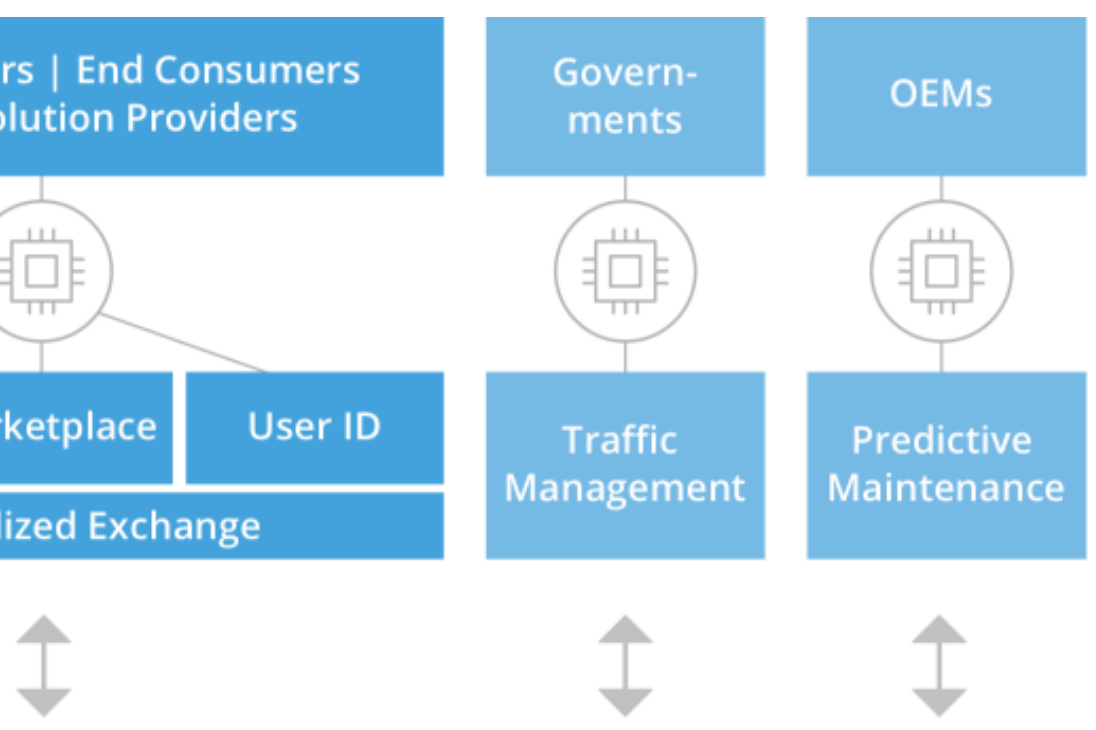

\section{全}

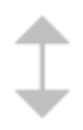

Distributed Ledger Platform 


\section{Conclusions}

- Blockchain as P2P protocol and infrastructure for distributed electricity market

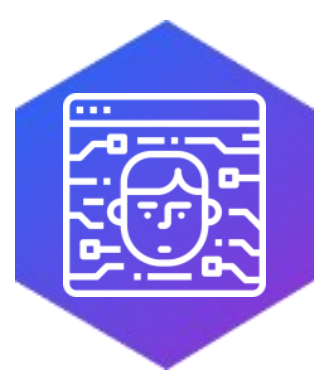

Energy assets ownership management

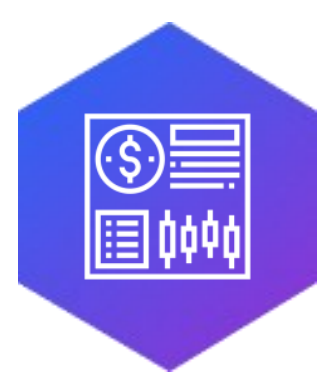

Settlement and clearing for energy trading

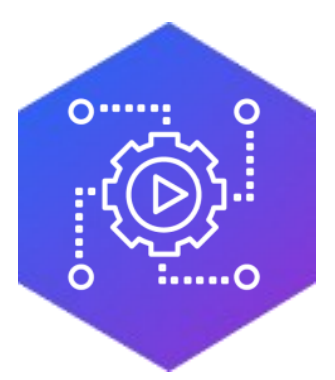

Economic infrastructure for P2P energy market

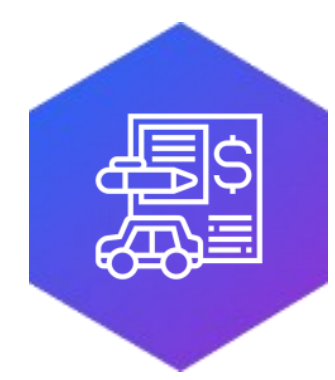

P2P ecosystem for Emobility market

\section{DIC SAT" 2019}




\section{Conclusions}

> Digital twin of Odesa city

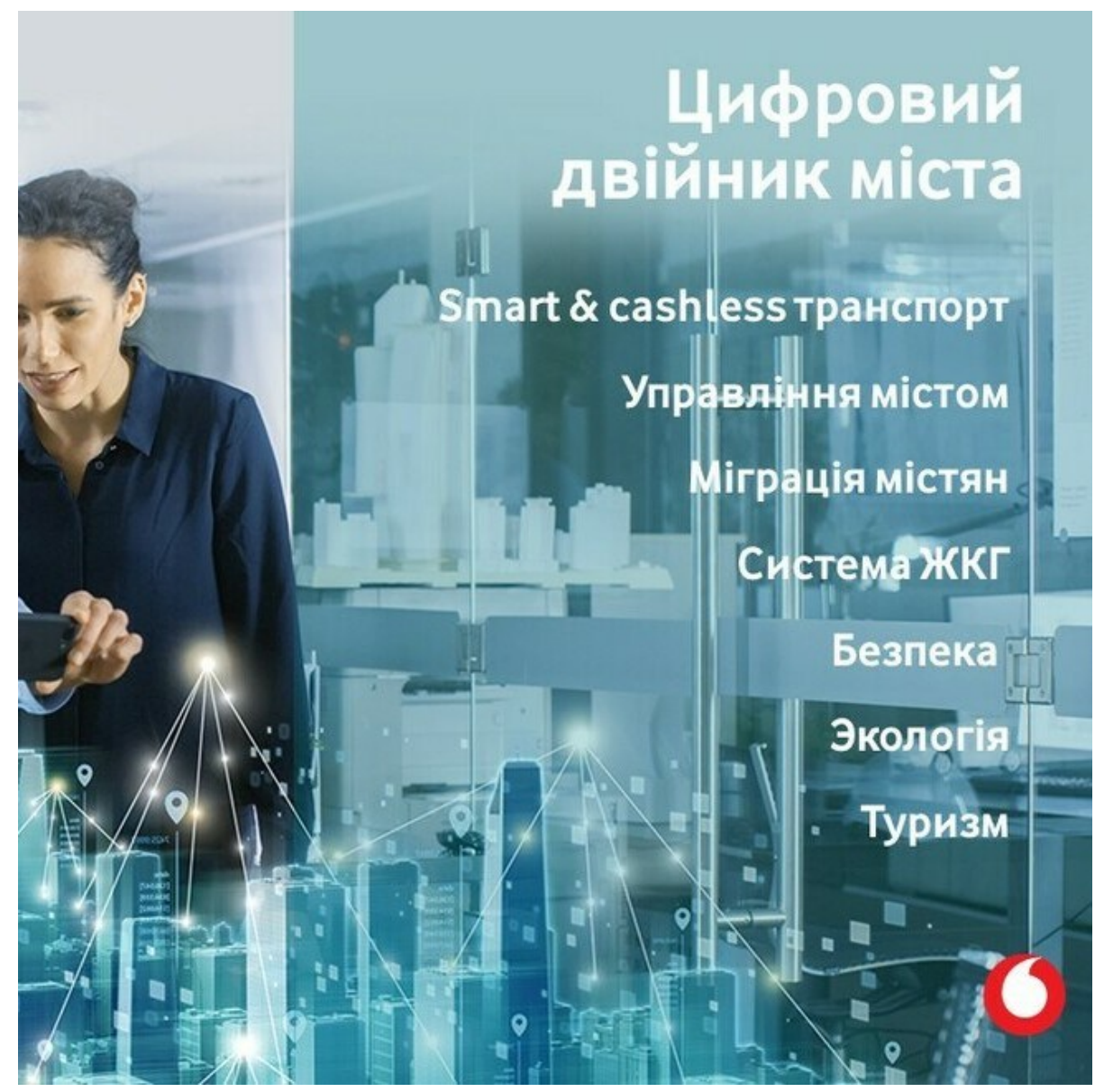




\section{धन्यवाद Gractas}

\section{Thank you for attention ! Děkuji za pozornost ! Dziękuję za uwage ! Дякую за увагу !}

